\title{
“EN GÜZEL DOKTOR FIKRALARI”NIN UYUMSUZLUK KURAMI BAĞLAMINDA İNCELENMESI
}

\author{
“THE MOST BEAUTIFUL DOCTOR JOKES” OF ANALYSIS IN THE CONTEXT \\ OF DISSONANCE THEORY
}

\section{Ferhat ÖZMEN*}

\begin{abstract}
ÖZ: Türk halk anlatıları içinde geniş bir yer tutan fikralar, birer kültürel bellek mekânı olarak toplumsal hayatta önemli bir boşluğu doldururlar. Yaşanmışlıkların eseri olan bu anlatılar, bazen bir meslek (doktor, polis, asker vb.) ya da karakter (deli, ahmak, hırsız vb.) ile ilgili olur ve fikralarda gülme "beklenen ile gerçekleșen arasındaki tutarsızlık/aykırılık" sonrasında gerçekleşir. Tutarsızlıkları/aykırılıkları gülmeyle ilişkilendiren Uyumsuzluk kuramına göre gülme eylemi, kalıplaşmış algıları yıkmak ve alışılmışın dışında bir sonuç ile karşılaşmak üzerinden gerçekleşir. Doktorluk mesleği ile ilgili fikralarda da gülmeye durum ve sunuş uyumsuzlukları/aykırılıkları neden olabilir. Bu çalışmanın amacı temel gülme kuramlarından biri olan Uyumsuzluk kuramını "doktor" konulu fıkralara uygulamaktır. Bu amaçla Deniz Dağıtım'ın hazırladığı En Güzel Doktor Fıkraları adlı eser kaynak olarak kullanılmış ve 207 fıkra metni incelenmiştir. Doktor konulu fikra metinlerindeki gülmeye sebep olan temel nokta, beklenen ve gerçekleșen arasındaki uyumsuzluktur. Anamnez sırasında doktorun mesajını yanlış anlayan ve bağlama uygun dönüt vermeyen hastalar, acemi doktorlar ve birbirinden farklı doktor ve hasta tipleri uyumsuz durumların ortaya çıkmasana neden olmuştur. Uyumsuzluğun görüldüğü fikralar dinleyicide ya da okuyucuda kalıplaşmış algıları yıktığı, çatışma yarattığı ve beklenenlere aykırı olduğu için “uyumsuzluk kuramı"nın aykırılık, zıtlık, beklenmezlik gibi ilkelerine sahiptir.
\end{abstract}

Anahtar Kelimeler: Doktor, fikra, uyumsuzluk kuramı, gülme.

ABSTRACT: Jokes, which occupy a wide place in Turkish folk narratives, fill an important gap in the social life as the place of cultural memory. These narratives, which are the result of experiences, are sometimes related to a profession (doctor, police, soldier) or a certain character (mad, idiot, thief) and laughter comes after "dissonance/contradiction between the expected and realized" in jokes. According to dissonance theory which associates dissonance/contradiction, laughter comes after through breking down stereotypes and encountering an unusual result. In doctor-related jokes the situation and presentation dissonances/contradictions may cause laughter too. The purpose of the present study was to apply the dissonance theory which is one of the basic laughter theories to doctor-related jokes. For this purpose, the book "The Most Beautiful Doctor Jokes", which was prepared by Deniz Distribution were used as a source; and 207 joke texts were examined. The essential point causing humor in doctor-related jokes is the incongruity between the expected and encountered situation. Patients who misunderstand the doctor's massage during the anamnesis and do not provide contextual feedback, inexperienced doktor and different types of doctors and patients have caused to arise encountered situationes. These texts, which were selected in line with the subject matter of the study, have the principles of "dissonance", "contrast", and "unexpected" of

\footnotetext{
* Öğr. Gör. Dr. - Samsun Üniversitesi / Samsun - ferhatozmenbey@hotmail.com (Orcid ID: 0000-0003-2969-5726)
}

This article was checked by Turnitin. 
the "the Dissonance Theory" because they break down the stereotyped perceptions in the listener or the reader, create conflicts, and are contrary to the expectations.

Keywords: Doctor, joke, the dissonance theory, laughter.

\section{Giriş}

Gülme eylemi, farklı duyguların etkisiyle insanın yüz ve karın kaslarının kasılıp gevșemesi ile ilgilidir. Söz konusu bu eylemin kaynağı tek merkezli değildir, pek çok şey gülmenin ortaya çıkmasına neden olabilir. Toplumsal yaşamda "katılığı esneklikle tadil etmek, her bireyin herkesle intibakını sağlamak, kısacası sivrilikleri yontmak" (Bergson, 2014: 114) gibi önemli fonksiyonları olan gülmenin doğasının ne olduğu ve gülmeye ne tür duyguların neden olduğu bütün yönleri ile açıklanamamıştır.

İnsan neden güler ya da mizah nasıl ortaya çıkar? Bu sorularına verilen cevaplar, gülme kuramlarını doğurmuştur. Üstünlük, rahatlama ve uyumsuzluk kuramları yanında, son yüzyılda geleneksel kuramları birleştirerek gülmeceye daha geniş bir bakış açısıyla yaklaşan çağdaş kuramlar gülmenin anlamı üzerine yorumlar getirmektedir.

“Gülmenin kişinin diğer insanlar üzerindeki üstünlük duygularının bir ifadesi" (Morreall, 1997: 2) olduğunu ileri süren ve en eski teori olarak kabul edilen üstünlük kuramında zafer duygusu öne çıkarılır. Aristoteles, zafer duygusunu; "Gülmece, ya başkasının aşağılandığını gördüğümüzde veya kendimizin geçmişte yaşadiğı ve aşağılandığı bir durumun hatırlanmasıyla verilen tepki neticesinde belirginleşen, kendimizde bir üstünlük algıladığımız zaman aniden uyanan üstünlük hissi." (Topuz, 1986: 27) şeklinde açıklar. Bu kuram gülmeyi bireyin diğer insanlar üzerindeki üstünlük duygularının ifadesi olarak ele alır. "Genel anlamda gülme başkasının hatası dolayısıyla insanın aniden kendinin üstün olduğu duygusuna kapılmasının bir sonucudur." ( Şentürk, 2010: 54).

Rahatlama (psikanalatik) kuramı, gülmenin fizyolojik boyutu üzerinde yoğunlaşır. Bu kurama göre gülme "Herhangi bir nedenle insanın içinde biriken sinirsel enerjinin boșaltılması sonucunda oluşur." (Usta, 2009: 86). Gülmenin rahatlatıcı etkisini ön plana çıkaran bu kuram, eğlenceli bir ruh haline girmeyi gülme ile ilişkilendirir. Beklenen ile gerçekleşen arasındaki tutarsızlığın/aykırılığın gülmeye neden olduğunu iddia eden uyumsuzluk kuramında ise mantıksız ve uygunsuz olaylar ve durumlar gülme nedeni olarak açıklanır.

Bu çalışmada "doktor" konulu fikralar uyumsuzluk kuramı açısından incelenerek hasta-doktor arasındaki ilişkiler, ön yargılar, iletişim ve iletişim çatışmaları vb. konular fıkra tahlilleriyle değerlendirilecektir. Fıkra metinleri Deniz Dağıtım'ın hazırladığı "En Güzel Doktor Fıkraları" adlı eserden seçilmiştir (En Güzel Doktor Fıkraları, 1984). 


\section{Uyumsuzluk Kuramı}

Uyumsuzluk kuramına göre kişiler mantık dışı ve istenmeyen/beklenmedik bir durumla karşılaştıklarında, kendileri ya da düşünceleri arasındaki bir uyumsuzluk yaşadıklarında gülerler. Gülme "umulmadık, mantıksız ya da şöyle ya da böyle uygunsuz olan bir şeye karşı gösterilen zihinsel bir tepki" (Morreall, 1997: 24) şeklinde tanımlanır. Bu zihinsel tepki umulmadık, mantıksız ve uygunsuz olaylar ve durumlara yönelik gerçekleştirilir.

Kuramın merkezinde şu düşünce yer almaktadır: "Nesneler, bu nesnelerin nitelikleri, olaylar vs arasında belirli kalıpları bulunmasinı beklediğimiz düzenli bir dünyada yaşamaktayız. Bu kalıplara uymayan herhangi bir şey başımıza geldiğinde güleriz." (Morreall, 1997: 25). Var olan kalıplara ters düşen ve bireyin beklentilerini boşa çıkaran durum ve olaylar gülmenin ortaya çıkmasına neden olur.

Uyumsuzluk teorisinde temel düşünce hem daha genel hem de çok daha basittir. Tabiatta var olan her şeyin, nesnelerin, nesnelerinin özelliklerinin ve olayların belli kalıpları, belli düzenleri vardır. Biz bu düzen içinde yaşarız. Bu kalıpların veya düzenlerin bozulması veya aksaması durumunda gülme meydana gelir (Türkmen, 1997: 47).

Bozulan kalıplar bireylerde şok etkisi yaratır ve algıdaki bu beklenmedik değişim de gülmenin ortaya çıkmasına neden olur.

\section{Doktor Konulu Fıkralar ve Bu Fıkralarının Fikra Tasniflerindeki Yeri}

Halk anlatıları içinde geniş bir yer tutan fıkralar, toplumların inanç ve değerlerini yansıtmada önemli bir görevi üstlenir. Yaşanmışlıkların ürünü olan bu anlatılar bir milletin hayatını, zevkini, dünya görüşünü yansıtır.

Fıkra, hikâye çekirdeğini hayattan almış, bir vaka veya tam bir fikrin teşkil ettiği kısa ve yoğun anlatımlı, beşeri kusurlarla içtimai ve gündelik hayatta ortaya çıkan kötü ve gülünç hadiseleri, çarpıklıkları, zıddiyetleri, eski ve yeni arasındaki çatışmaları, sağduyuya dayalı ince bir mizah, hikmetli bir söz, kekin bir istihza yolu ile yansıtan; umumiyetle bir fikra tipine bağlı olarak nesir dili ile yaratılmış, sözlü edebiyatın müstakil şekillerinden ibaret yaygın epik-dram türündeki realist hikâyelerden her birine verilen isimdir (Yildırım, 1999: 3).

Fıkralar üzerine çeşitli tasnif çalışmaları yapılmıștır. Bu tasnif çalışmaları göz önüne alındığında doktor konulu fıkralar, Mehmet Tuğrul'un "Başka fikralar" (Tuğrul, 1969:344), Pertev Naili Boratav'ın "Belli bir topluluk, tip, ünlü bir kişi olmaksızın, ortadan insanların güldürücü maceralarını konu edinen fikralar" (Boratav, 1969:407), Dursun Yıldırım'ın "Gündelik fikra tipleri” (Yıldırım, 1999:32), Saim Sakaoğlu'nun "Bir karakter veya meslek grubu ile ilgili olanlar" (Sakaoğlu, 1992:44) madde başlıkları altında değerlendirilebilir. Bu fikralar bir topluluğu temsil eden tipler etrafında teșekkül eden fikralara örnektir. 
"Doktor fikraları aslında bir türü değil, bağlamı, yani içinde doktorun geçtiği çeşitli fikraları imleyen bir terimdir." (Kebeli, 2005: 101). İçinde doktorun yer aldığı ve doktorluk mesleği ile ilgili fikralar, uyumsuzluk kuramı bağlamında çözümlenebilir.

\section{Uyumsuzluk Kuramının Doktor Konulu Fıkralara Yansıması}

Gülmenin mantık ve düşünce yönüne ağırlık veren uyumsuzluk kuramı, mantıksız ve uyumsuz olan her şeyin gülmeye neden olabileceğini kabul eder. Kurama göre uyanık bir zihnin olaylar ya da durumlar arasındaki uyumsuzluğu hızla fark etmesi gerekir. Aksi durumda "beklenmezlik ve şaşkınlık" unsurları hayat bulamaz. Bireyin zihin esnekliği gülmenin ortaya çıkmasında önemli rol oynar.

Doktor konulu fikralarda, uyumsuzluk kuramının "olması beklenen ile olan arasındaki tutarsızlı̆̆ın" gülmeyi doğurduğunu kabul eden görüşünü destekleyen örneklere rastlanır. Aşağıdaki fikra uyumsuzluk kuramının temel görüşünü çok iyi açıklar:

"Temel bir gün ameliyat olacakmış. Doktorlar maskeyi takınca Temel:

-Boşuna maske takmayın, hepinizi tanıyorum demiş." (www. fikralarim.com.tr)

Söz konusu fikrada Temel'in sözleri genel mantık kurallarına terstir. Çünkü doktorlar ameliyat öncesi maske takar ve bu durum onların işleri gereğidir. Temel'in mantık düzleminde ise tanınmak istemeyen bireyler maske takar. İki farklı mantık düzlemindeki çelişki, gülmenin ortaya çıkmasına neden olur.

Temel Fıkraları'nın pek çoğunda bir fikra tipi olarak 'Temel'in özellikle değişik Türkçe kullanımı ve aptallığının vurgulanması yoluyla bir güldürü nesnesi olarak yer alması, Lazlar özelinde Karadenizlilere yönelik belirli bir 'stereotipleştirme' ve 'ötekileştirme' etkinliğinin gerçekleştirilmiş ya da gerçekleşmekte olduğuna işaret ediyor olarak yorumlanabilir (Sheridan Aksoy, 2007: 98).

Temel'e bağlı olarak anlatılan fikraların çoğunda Temel, alışılmadık biçimde yürüttüğü mantığı ile insanları güldürür. Bu fıkrada da maskeyi bağlam dışında yorumlayan Temel, gülmenin/uyumsuzluğun ortaya çıkmasına neden olur.

Doktor konulu fikralarda çoğu zaman anlam kargaşasının neden olduğu uyumsuzluklara dikkat çekilir. "Uyumsuzluk kuramında uyumun içindeki uyumsuzluğun vurgulandığını söylemek yanlış olmaz." (Tufan, 2007: 109). Konuşan kişinin niyetinin yanlış anlaşıldığı fikralarda beklenen ile gerçekleşen arasındaki uyumsuzluk gülmenin ortaya çıkmasına neden olur. Flkra metinlerinde kahramanlar kimi sözcük ya da sözcük öbeklerini bağlam dışında yorumlar. Bu yorumlar iletişim çatışmalarının ortaya çıkmasına neden olur. Aşağıdaki fikrada doktorun sorularına bağlam dışında cevap veren hastanın uyumsuzluğu, fıkrayı okuyan ya da dinleyen bireyi güldürür: 
"Doktor hastasına sormuş:

Neyiniz var?

- Íki dairem, bir kotram, bir de otomobilim var.

- Onu sormadım efendim, yani şikâyetiniz nedir?

-Ah doktor ah! Benim çocuklardan şikâyetçiyim. Çekmediğim kalmıyor afacanlardan.

- Bana bakın, onu sormuyorum size. Hastalığınız nedir hastalığınız?

- Illahi doktor! Benimle dalga mı geçiyorsunuz? Hastalığımın ne olduğunu bilsem size gelir miyim?” (En Güzel Doktor Fıkraları, 43).

Çok anlamlı sözcüklerin bağlam dışında yorumlanması doktor-hasta diyaloğunda bir uyumsuzluk/tezatlık yaratır. Fıkrada tıp literatüründe “anamnez" şeklinde açılklanan hasta ile ilk söyleşide doktor, "Neyiniz var?”, "Şikâyetiniz nedir?" gibi sorular sorarak hastanın sağlık durumunu öğrenmeye çalışır. Ancak hasta, doktorun sorularına başka bir mantık düzleminden cevap verir. Bağlama uygun olmayan cevaplar da gülmecenin ortaya çıkmasına neden olur.

Doktorun sözlerini anlamıyor görünen hasta, varoluş çatışması örneği sergiler. Hastanın farklı cevapları, "Çatışmaya neden olan sebeplerin bilinçaltına atıldığını göstermektedir." (Şenocak 2005: 152). Doktorun beklediği cevapları ısrarla vermeyen hasta, bastırdığı hastalık ihtimalleriyle doktoru farklı yönlendirerek gülmeye neden olur. Sonuçta rahatsızlandığı için doktora giden hasta, doktora, hastalı̆̆ının adını koyması gerektiğini söyleyerek doktorun meslek bilgisini eleştirir, bu durum da gülmeye yol açar. Anlam karmaşasının neden olduğu bir başka fıkrada da doktorun mesajını bağlam dışında yorumlayan hasta, herkesi kendine güldürür:

"Doktor sabah vizitesine çıkmıştı koğuşta. Her yatağın önünde duruyor ve hastaya soruyordu:

-Iddrar durumun nasil?

- Çarpintın var mi?

-Kaşıntı maşıntı filan?

-Ağrı var mı?

-Sancin var mi?

Bir köylünün yanında durdu:

-Ateşin var mı?

Adam hemen doğruldu, pijamasının cebinden telaşla kibritini çıkarıp uzattı:

-Buyurun doktor bey." (En Güzel Doktor Fıkraları, 22)

Anlam karışıklığının neden olduğu uyumsuzlukta varoluşsal bağlamda bir iletişimsizlik yaşanır. Mesajın başka anlamda yorumlandığı fıkrada köylü “ateş" sözcüğünün çok anlamlı olmasının kurbanı olur. "Bildirişim tek bir olay değil, belli bir noktadan başlayıp adım adım gelişerek belli bir noktada sona eren bir olaylar dizisi, art arda siralanan bir olaylar zinciridir; bir süreçtir." 
(Ünalan, 2005: 131). Doktorun cevabına uygun dönüt veremeyen hastanın durumu iletişim sürecinin sağlıklı yürümediğini gösterir.

Sözcük ya da sözcük öbeklerinin ima edilen anlamlarından ziyade sözlük anlamlarında kabul edilmesi uyumsuz durumların ortaya çıkmasına neden olur. Așağıdaki fikrada ilacın üzerindeki mesajı yanlış yorumlayan hastanın durumu söz konusu edilen uyumsuzluğu örnek verilebilir. Fıkrada olay şöyle anlatılır:

"Doktor hastasını ziyarete gittiğinde:

-Maşallah, dedi. Sizi gayet iyi buldum. Demek verdiğim ilaç iyi gelmiş.

-Evet, doktor bey iyiyim, dedi hasta.

-Verdiğiniz ilaç şişesindeki tembihi tutum.

- Neymiş acaba o tembih?

-Şişenin üzerinde 'ağzı kapalı saklayınız' yazıyordu. Ben de aynısını yaptım." (En Güzel Doktor Fıkraları, 109).

Mantıksızlığın gülmeye yol açabilmesi için kendi içinde bir mantık dizgesine sahip olması gerekir. Bu bağlamda uyumsuzluk kavramı etrafında gülme, mantıksız olan ile normal olan arasında ortaya çıkan paradoksal çerçeve üzerine gerçekleşir. Yukarıdaki fikrada ilaç şişesindeki ifade hastanın mantık düzleminde farklı, doktorun mantık düzleminde farklı anlamlandırılır. İlacın üzerindeki "ağzı kapalı saklayın" mesajı onun bozulmasını önlemeye yönelik tedbirleri içerir. Hastanın bu iletiye yorumu ise ilacı kullanmadan saklamak şeklindedir. Söz konusu bu yorum/mantıksızlık gülmeyi doğurur.

Belli bir ortamın belli davranışları olması gibi basit bir olay örgüsü, bozulunca gülme refleksi doğurur. Buradaki ayrım, nesne veya durumun uyumsuzluğu ile bir insanın o nesneyi veya durumu temsil edişindeki uyumsuzluk olarak karşımıza çıkar. Araştırıcılar buna 'şeylerdeki uyumsuzluk' (incongruity in tings) ve 'sunuştaki uyumsuzluk' (incongruity in presentation) demektedirler (Türkmen, 2021: 1415).

Doktor konulu fikralarda durum ve sunuş uyumsuzluğunun neden olduğu gülmece örneklerine çok sık rastlanır. Özellikle acemi doktorlarının eleştirildiği fikralarda uyumsuz durumlar, mizahın ortaya çıkmasına neden olur. Aşağıdaki fikrada "bu kadarına da pes" dedirtecek cinsten bir acemiliğe/beceriksizliğe ve mesleki uyumsuzluğa dikkat çekilir:

"Adam son derece tehlikeli bir ameliyat geçirecekmiş. Kurbanlık koyun gibi uzanmış ameliyat masasına.

-Ne dersiniz doktor? Kazasız belasız atlatabilecek miyim bu ameliyatı?

Doktor:

-Vallahi kardeşim, bu ameliyatı doksan ikinci kez yapıyorum. Kafaya koydum, evvel Allah bu kez ne yapıp edip başaracağım, demiş." (En Güzel Doktor Fıkraları, 72)

Doktorluk/hekimlik profesyonel tıp mesleğinin icra edildiği bir meslek koludur. Bu alanda hastalara cerrahi müdahale bulunan doktorların 
uzman/tecrübeli olması beklenir. Yukarıdaki fıkrada bu beklentinin aksi söz konusudur.

Uyumsuzluğu oluşturan asıl etken, insan zihninde kategorize edilen olayların ve durumların beklentilere ters düșmesi ve var olan kalıpların bir anda yıkılmasıdır. Yıkılan kalıplar insanı şoke sokar, algıdaki bu sürpriz değisşim gülmeye yol açar (Sağlam, 2013:104).

Beklentileri boşa çlkaran ve defalarca tıbbi müdahalede bulunan ancak bir sonuç alamayan doktorun durumu şaşkınlık doğurur. Mesleki profesyonellikten uzak bir doktorun durumu aşağıdaki fikrada da tezatlık yaratır:

"Doktor mide ağrısından şikâyet eden hastayı bir güzel azarlamaya başlamıș:

-Doktor sözü dinlemeyenin hali budur iște! Ben size demedim mi günde yalnızca yarım paket sigara içeceksiniz diye?

Hasta ezilmiş büzülmüş:

-Öğüdünüze uydum doktor bey, emin olun günde yarım paketten fazla sigara içmiyorum. Gerçi onu içinceye kadar da anam ağliyor ya ne ise. Ne yaparsınız bu yaștan sonra sigaraya başlamak hiç de kolay değil." (En Güzel Doktor Fikraları, 36).

Hastalığın çok farklı sebepleri vardır, hastalığ tek bir nedene bağlamak ve bu neden etrafında hastaya tavsiyelerde bulunmak yanlıștır. Fıkrada mide ağrısını sigara ile ilişkilendiren ve hiç sigara içmeyen hastaya sigara içmeyi öneren doktorun durumu gülmeceye neden olur. Acemi doktorun eleştirildiği fıkrada, doktorların doğru teşhis ve tedavi yöntemleri uygulaması gerektiği imlenir.

Söz konusu fikralarda aynı zamanda doktorluk mesleğinin önemine vurgu yapılır ve doğru teşhisin üzerinde durulur. "Yarım doktor candan, yarım hoca imandan eder.", "Cerrahın/doktorun hatasinı toprak örter.", "Doktor bazen hayat kurtarır bazen de hayat karartır." sözleri doktorluğun hassas bir meslek olduğunu dile getirir.

Flkra metinlerinde olay örgüsünün gidişatında ani bir sapma uyumsuzluk yaratır. Metinlerde olaylar belli bir mantık kategorisinde gerçekleşir ve bu olaylar arasındaki sapmalar tezatlık yaratır. Aşağıdaki fıkrada olay örgüsündeki uyumsuzluk gülmecenin ortaya çıkmasına neden olur.

"Adamın birini kuduz köpek ısırmış. Ama adam ihmalci olduğu için bugün iğne olurum yarın iğne olurum derken iş işten geçmiş. Doktora başvurup da gerçeği anlayınca hemen bir kâğıt kalem isteyip uzun uzun bir șeyler karalamaya başlamış.

Doktor uzun süre beklemiş, bir ara dayanamayıp hayretle sormuş:

-Vasiyetnameniz bu kadar uzun mu?

-Vasiyetname hazırladığımı söyleyen kim doktor? Ben ısıracağım kişilerin listesini yazıyorum."(En Güzel Doktor Fıkraları, 16). 
Söz konusu fikrada ölmek üzere olan bir hastanın vasiyet yazmak yerine ısıracağı insanların isim listesini yapması tezatlık yaratır. Fıkrada hasta, mecazi ifadelerle kuduzu başka insanlara da bulaştırmayı onların canını yakmayı amaçladığını dile getirir. Mantığı aykırı bu durum gülmeye neden olur.

Uyumsuzluk kuramına göre kişiler mantık dışı, istenmeyen veya beklenmedik bir durumla karşılaştıklarında gülerler. Kendileri ya da düşünceleri arasındaki uyumsuzluk gülmenin ortaya çıkmasına neden olur. Zihinsel bir tepki olan gülme umulmadık, mantıksız ve uygunsuz olaylar ve durumlara yönelik gerçekleştirilir.

\section{Sonuç}

Bireyin tuhafına giden durumlar, olaylar ve ifadeler karşısında sesli bir şekilde duygusunu ifade etmesi gülme kavramı ile açıklanır. Kalıplaşmış algıları yıkmak ve alışılmışı dışında bir sonuç ile karşılaşmak gülmenin ortaya çıkmasına neden olur.

Doktor konulu fikralar dinleyicide ya da okuyucuda kalıplaşmış algıları yıktığı, çatışma yarattığı ve beklenenlere aykırı olduğu için "Uyumsuzluk Kuramı"nın aykırılık, zıtlık, beklenmezlik gibi ilkelerine sahiptir. Söz konusu fikraların uyumsuzluk kuramının bu ilkelerine sahip olması metinlerin kuram bağlamında çözümlenebileceğini ortaya koymuştur. Kuramın özelliklerini sahip fikra metninin birçoğunda doktor ve hastaların münasebetsizlikleri, beklenmeyen çıkışları ve uyumsuz durumları tespit edilmiştir.

Fikralarda toplumun genelinden ayrlan doktor ve hasta tiplerinin uyumsuzluklarına rastlanmıștır. Anamnez sırasında doktorun mesajını yanlış anlayan ve bağlama uygun dönüt vermeyen hastalar, acemi doktorlar ve birbirinden farklı doktor ve hasta tipleri uyumsuz durumların ortaya çlkmasana neden olur. Hasta-doktor ve hasta-çevre ilişkilerindeki tutarsızlıklar üzerinden gerçekleşen gülmeler, uyumsuzluk kuramının beklenen ile gerçekleşen arasındaki tutarsızlığın/aykırılığın gülmeye neden olduğunu iddia eden görüşü ispatlar.

\section{KAYNAKÇA}

\section{Yazılı Kaynaklar}

Bergson, H. (2014). Gülme. (Çev.: Devrim Çetinkasap), İstanbul: Türkiye İș Bankası Kültür.

Boratav, P. N. (1969). Az gittik uz gittik. Ankara: Bilgi.

En güzel doktor fikraları (1984), İstanbul: Deniz Kitaplar.

Kebele, S. (2005). Doktor fikraları. Millî Folklor, S. 67, 98-101.

Morreall, J. (1997). Gülmeyi ciddiye almak. (Çev. Kubilay Aysevener, Şenay Soyer), İstanbul: İris.

Sağlam, M. (2013). Bektaşi fikralarının uyumsuzluk kuramı bağlamında incelenmesi. Milli Folklor, S. 98, 100-108. 
Sakaoğlu, S. (1992). Türk fikraları ve Nasreddin Hoca. Ankara: Selçuk Üniversitesi Basımevi.

Sheridan Aksoy, R. A. (2007). Temel fıkralarında ötekileştirme boyutu. Millî Folklor, S. 75, 95-103.

Şenocak, E. (2005). Nasreddin hoca fikralarında gizli diller. I. Uluslararası Akşehir Nasreddin Hoca Sempozyumu Bildirileri-Akşehir, 145-156.

Şentürk, R. (2010). Gülme teorileri. İstanbul: Rasyo.

Topuz, H. (1986). İletişimde karikatür ve toplum. Eskişehir: Anadolu Üniversitesi.

Tufan, Y. (2007). Uyumsuzluk kuramı bağlamında sanal ortamda temel fikraları. Millî Folklor, S. 75, 108-112.

Tuğrul, M. (1969). Mahmutgazi Köyünde halk edebiyatı. İstanbul: Milli Eğitim Bakanlığı.

Türkmen, F. (1996). Modern mizah teorilerine göre Nasreddin Hoca fikralarının yorumu. Uluslararası Nasreddin Hoca Bilgi Şöleni (Sempozyum) Bildirileri 2426 Aralık, İzmir, (Hzl.: Alev Kâhya Birgül), 47-52, AKM.

Türkmen, F. (2021). Modern mizah teorilerinden uyumsuzluk teorisi ve Nasreddin Hoca fıkraları. Doğan Kaya Armağanı Cilt 2, 1411-1418, Sivas: Vilayet Kitapevi.

Usta, Ç. (2009). Mizah dilinin gizemi. Ankara: Akçağ.

Ünalan, Ş. (2005). Dil ve kültür. Ankara: Nobel.

Yıldırım, D. (1999). Türk edebiyatında Bektaşi fıkraları. Ankara: Akçağ.

\section{Elektronik Kaynaklar}

URL-1: http://www.fikralarim.com/maske.html (Erişim: 06.04.2021)

“İyi Yayın Üzerine Kılavuzlar ve Yayın Etiği Komitesi'nin (COPE) Davranıș Kuralları” çerçevesinde aşağıdaki beyanlara yer verilmiştir. / The following statements are included within the framework of "Guidelines on Good Publication and the Code of Conduct of the Publication Ethics Committee (COPE)":

İzinler ve Etik Kurul Belgesi/Permissions and Ethics Committee Certificate: Makale konusu ve kapsamı etik kurul onay belgesi gerektirmemektedir. / The subject and scope of the article do not require an ethics committee approval.

Çıkar Çatışması Beyanı/ Declaration of Conflicting Interests: Bu makalenin araștırması, yazarlığı veya yayınlanmasıyla ilgili olarak yazarın potansiyel bir çıkar çatışması yoktur. / There is no potential conflict of interest for the author regarding the research, authorship or publication of this article. 